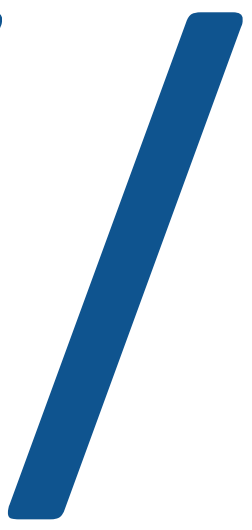

\title{
Las rupturas del 68 en el cine de América Latina, coordenação de Mariano Mestman
}

Las rupturas del 68 en el cine de América Latina, edited by Mariano Mestman

Carolina Amaral de Aguiar ${ }^{1}$

'Pós-doutoranda em Cinema pela ECA-USP, com bolsa FAPESP. Doutora em História Social pela FFLCH-USP (2013). Mestre em Estética e História da Arte (2007), bacharelado (2002) e licenciatura (2003) em História pela Universidade de São Paulo (USP). E-mail: amaral_carol@yahoo.com.br 
Resumo: Las rupturas del 68 en el cine de América Lati$n a$, organizado por Mariano Mestman, analisa as rupturas ocorridas em distintas cinematografias da América Latina - Argentina, Bolívia, Brasil, Chile, Colômbia, Cuba, México e Uruguai - em torno a 1968. O ano é pensado como símbolo de uma "época", palco de contestações políticas e proposições vanguardistas em diferentes partes do mundo. Mestman pretende entender como essas rupturas incidiram em cada caso nacional, convidando autores de distintas nacionalidades para analisarem as transformações cinematográficas em seus respectivos países. O livro traz ainda, em sua segunda parte, artigos que pensam essas rupturas em uma perspectiva transnacional.

Palavras-chave: cinema latino-americano; 1968; vanguardas cinematográficas; engajamento político; Nuevo Cine Latinoamericano

Abstract: Las rupturas del 68 en el cine de América Latina, edited by Mariano Mestman, analyses breaks that affected different cinematographies in Latin American - Argentina, Bolivia, Brazil, Chile, Colombia, Cuba, Mexico and Uruguay - around 1968. This year is considered like a symbol of an "era" characterized by political contestations and avant-garde propositions around the world. Mestman intends to understand how these breaks affect each country, inviting authors from many nationalities to think about the changes in the cinematographies of their countries. The book also brings in its second part three texts about these breaks in a transnational view.

Key words: Latin-American cinema; 1968; avant-garde cinema; political engagement; Nuevo Cine Latinoamericano 
Lançado em 2016 pela editora Akal, em Buenos Aires, Las rupturas del 68 en el cine de América Latina se junta a uma série de obras publicadas nos últimos anos que revisitam o Nuevo Cine Latinoamericano (NCL). Entre elas, pode-se destacar os trabalhos de Isaac León Frias (2013), Silvana Flores (2013), Carlos Ossa (2013) e Ignacio Del Valle Dávila (2014). Nota-se que apenas o primeiro foi escrito por um participante desse fenômeno cinematográfico; León Frias era o diretor da revista Hablemos de cine, palco de importantes discussões nos anos 1960 e 1970. Nesse contexto de um revigorado interesse pelo tema, Las rupturas..., organizado por Mariano Mestman, surge como um título incontornável para os estudos sobre o NCL, corroborando a tendência atual de um olhar menos testemunhal e mais ligado à pesquisa acadêmica. Porém, em termos estruturais, o livro se diferencia dos demais por ser uma coletânea de textos, de autores que são referências em seus lugares de origem, que escrevem normalmente sobre processos ocorridos no interior de seus próprios países. Dessa forma, sem desconsiderar o caráter continental do fenômeno, marcado por rupturas estéticas e políticas, Mestman opta por uma abordagem que verifique a incidência dessas rupturas nas distintas cinematografias locais.

Outro diferencial de Las rupturas... é a proposta de condensar as mudanças ocorridas no cinema latino-americano do período em torno de um ano simbólico: 1968. Assim, o organizador opta por estabelecer uma baliza temporal que enfatiza a contestação política e cultural desse ano, que viu surgir uma nova esquerda e o fortalecimento da contracultura. A escolha por falar de 1968 relaciona o NCL aos fenômenos globais que o circundam, na Europa e nos Estados Unidos, embora pretenda-se, no livro, entender como eles afetam cada um dos distintos países do continente. Mestman indica, na apresentação da obra, que entende esse ano em uma perspectiva de longa duração, encarando-o como uma "época" ou um "momento 1968”, como o define. O autor se apoia na ideia de Fredric Jameson (1984) de uma "longa década de 1960", que vai da segunda metade dos anos 1950 até o começo dos 1970. Tendo como referência ainda o estudo de Claudia Gilman (2003), sugere que para a América Latina esse "momento" esteve profundamente marcado pela Revolução Cubana (1959) e seus desdobramentos e, como um anticlímax, pelo golpe de Estado no Chile (1973).

Ao ano 1968 é atribuído um caráter de quebra, de mudança. Aos distintos autores, foi proposto o desafio de tratar dessas rupturas (vistas como um "conceito chave e no plural", como indica Mestman na apresentação) em seus contextos nacionais. A obra se divide em dois blocos, sendo o primeiro deles claramente o principal. $\mathrm{Na}$ parte I, estão representadas a maioria das cinematografias latino-americanas im- 
portantes para o NCL: Argentina, Bolívia, Brasil, Chile, Colômbia, Cuba, México e Uruguai. Essa escolha editorial relega o objetivo de pensar o caráter em si transnacional presente na reivindicação de um Nuevo Cine Latinoamericano. Ao contrário, trata-se, como anuncia o texto de abertura, de pensar o que há de latino-americano em cada uma dessas cinematografias.

No livro, os estudos abertamente transnacionais se resumem aos três artigos presentes na parte II, "El documental, la televisión y la industria cultural", que se constitui como uma espécie de posfácio - um pouco apartado, na verdade, do cerne da proposta editorial. Dos três capítulos finais, apenas o de María Luisa Ortega, "Mérida 68. Las disyuntivas del documental" parece servir como um verdadeiro fechamento, uma vez que, ao abordar o festival ocorrido na Venezuela, a autora percorre as distintas cinematografias tratadas na primeira parte. "Industria cultural e identidad nacional. Dos films emblemáticos”, de Paula Halperin, propõe-se a encontrar pontos em comum no papel que Martín Fierro (1968), de Leopoldo Torre Nilsson, e Macunaíma (1969), de Joaquim Pedro de Andrade, desempenharam nas cinematografias argentina e brasileira, respectivamente, ao integrarem cinema de autor e elementos comerciais a uma reflexão sobre a nação. Assim, trata-se de uma análise interessante e inovadora, mas que no livro aparece um pouco desconectada da proposta apresentada pelo editor. Essa sensação de uma leitura complementar aparece, sobretudo, no capítulo "Con y contra el cine y la televisión", de Mirta Varela, que se dedica a entender como a televisão foi vista na Europa e na América Latina diante das novas inquietações políticas, culturais e estéticas acarretadas pelos acontecimentos de 1968. De qualidade inquestionável, sem dúvida esse texto é o mais deslocado quando se analisa o conjunto de Las rupturas...

Ciente de que a abordagem nacional não é a mais frequente para tratar do fenômeno do NCL, Mestman justifica, na apresentação, que o objetivo de se aprofundar nas características singulares de cada país vem da valorização dos filmes, ao mesmo tempo produtos e agentes das rupturas estéticas, culturais e políticas que se produzem na América Latina da época. O coordenador de Las rupturas... demonstra clareza sobre os ganhos e as perdas desse caminho metodológico. Para ele, não se trata de negar a existência de "[...] fortes vínculos materiais entre os cineastas, muitos deles com epicentro no ICAIC cubano ou nos festivais regionais [...]”, mas sim de considerar que:

[...] os filmes que se realizam são em sua maior parte sobre uma realidade "nacional", e, embora se remetam muitas vezes à situação regional (de subdesenvolvimento, dependência ou insurreição), focalizam em um caso, o país em que são realiza- 
dos ou o de origem do cineasta (em especial quando, desde o exílio, se denuncia a situação repressiva) (MESTMAN, 2016, p. 15).

Como resultado dessa proposta, é possível perceber que, lidos em conjunto, os textos da primeira parte apresentam uma espécie de filmografia latino-americana dos anos 1960 e 1970 composta por diferentes vertentes dessas rupturas estéticas, culturais e políticas. São muitos os títulos citados; de modo geral, cada autor se coloca o desafio de encontrar obras paradigmáticas em suas cinematografias nacionais que enfrentaram a estrutura narrativa do cinema clássico de Hollywood e que, em sua maioria, articularam essa renovação das formas com um discurso político revolucionário. Porém, nessa ampla gama de filmes, verifica-se que essas rupturas de 1968 estão envoltas em tensões que passam, sobretudo, pela relação, às vezes conflituosa, entre vanguarda artística e vanguarda política, cinema de autor e cinema coletivo, contracultura e engajamento.

Os capítulos de Las rupturas... colocam em destaque processos políticos internos dos países que incidiram diretamente nas cinematografias locais, como a morte de Camilo Torres (1966), na Colômbia, o AI-5 (1968), no Brasil, ou as agitações do movimento estudantil (1968), no México (1968). Assim, 1968, entendido como uma "época" ou um "momento", foi uma data de fortes embates entre revolução e repressão, dentro e fora da América Latina. É incontornável, apesar da ênfase no nacional, que os capítulos façam referências a um certo clima global, seja em relação às rupturas estéticas (como os "novos cinemas" ou a contracultura), seja em relação aos debates políticos sobre a questão do terceiro mundo. Também se torna impossível para os autores não tocarem no significado simbólico de 1968 como um ano que representou a afirmação da juventude como um importante protagonista político tanto na Europa como no continente latino-americano. Nesse sentido, vários textos abordam à noção de geração, como bem observou Mestman na apresentação, envolvida nessas rupturas.

Convém recorrer brevemente os capítulos da parte I, "Casos nacionales", chamando atenção para como algumas das questões apontadas até aqui aparecem nos textos que a compõem. Em "Argentina: el profano llamado del mundo", David Oubiña define os anos 1960 como uma década "hipertélica" tanto em sua dimensão militante como na experimental, marcada por uma pulsão extrema entre "vanguarda estética" e "radicalização política". No entanto, se até meados dos 1960 a fronteira estética ideológica entre os cineastas era bastante permeável - sendo o "ideológico", segundo o autor, definido pelo amplo conceito do "compromisso" -, a partir do golpe 
de Estado de Onganía (1966) as redefinições do debate político afetaram também a coexistência de diferentes poéticas. Nesse sentido, as novas discussões surgidas após 1968 na cinematografia argentina podem ser sintetizadas por filmes como La hora de los hornos (A hora dos fornos, 1968), de Octavio Getino e Fernando Solanas, e Invasión (Invasão, 1969), de Hugo Santiago, que habitam, para Oubiña, “[...] universos ideológicos tão incompatíveis como incomensuráveis" (2016, p. 86) - terceiro e segundo cinema, conforme a nomenclatura proposta por Getino e Solanas. O questionamento radical da representação e a ruptura com um cinema narrativo, presente no que foi chamado de cinema experimental, tensionaram ainda mais o debate. $\mathrm{O}$ autor afirma que produções como The players vs. Ángeles caídos (The players vs Anjos caídos, 1969), de Alberto Fischerman, chegaram a ser vistas como uma espécie de "quarto cinema". Dessa forma, o final da década trouxe enfrentamentos entre "cineastas militantes e vanguardistas" que, para Oubiña, se tornariam inconciliáveis no início da década seguinte.

Assim como o capítulo sobre a Argentina, o dedicado à Bolívia, de autoria de Javier Sanjinés, indica alguns filmes chaves dos anos 1960, como Revolución (Revolução, 1963), Ukamau (1965) e Yawar Mallku (O sangue do condor, 1969), todos de Jorge Sanjinés. No entanto, a ruptura na cinematografia boliviana da qual trata o autor em "La estética transculturadora de una revolución frustrada" não está tanto na dicotomia entre estética e política, mas na passagem de uma "transculturação desde cima" a uma "transculturação desde baixo". O texto analisa a filmografia de Jorge Sanjinés e do Grupo Ukamau refletindo sobre seu diálogo com as vanguardas cinematográficas internacionais e as "condições espaço-temporais andinas que a complicam e questionam” (2016, p. 127). Dessa forma, o autor defende que Revolución trazia uma renovação estética ao incorporar elementos da modernidade europeia, mas não rompia com um olhar colonizador. A partir de Ukamau e Yawar Mallku, Jorge Sanjinés privilegiou a oralidade indígena, sem romper, no entanto, com "conteúdos narrativos das décadas anteriores". De acordo com o texto, somente a partir dos anos 1970, particularmente com El coraje del pueblo (A coragem do povo, 1971) e La nación clandestina (A nação clandestina, 1989), o cineasta boliviano romperia com o paternalismo de certas formas narrativas rumo à "transculturação desde baixo".

Do capítulo sobre o Brasil, "Alegorías del subdesarrollo", novamente se pode extrair uma filmografia referencial do período, na qual estiveram presentes questões centrais do campo cinematográfico, mas tratadas sob resultados estéticos bastantes diversos. Entre os filmes citados por Ismail Xavier, os de Glauber Rocha e de Rogério Sganzerla se destacam como propostas de se pensar a nação brasileira a 
partir de um diagnóstico comum: a condição de subdesenvolvimento. Deus e o diabo na Terra do Sol (1964), de Rocha, é apontado como uma "obra-síntese", de ruptura, ao combinar inovação formal com "a alegoria que resulta do afã de pensar o destino nacional” (2016, p. 155). Dessa forma, Deus e o diabo... marcaria a alegoria como forma de conceber a "história como teleologia", sendo a revolução o destino final que dá sentido ao anterior. Porém, os filmes do final da década de 1960, realizados sob a ditadura militar, abrem mão desse olhar teleológico, "[...] marcando um corte frente a representações anteriores da história, passagem que encontrou seu término nas expressões apocalípticas provenientes da nova geração que rompeu com o Cinema Novo no final da década" (2016, p. 157). A ruptura ocorrida nesse período pode ser verificada em Terra em transe (1967), de Rocha, e O bandido da luz vermelha (1968), de Sganzerla. A análise desses dois filmes, feita no capítulo por Xavier, se centra na polêmica que envolveu a geração do Cinema Novo e aquela do cinema marginal (visto como grupo), definida pelo autor como a passagem da "estética da fome" à "estética do lixo".

No caso do capítulo sobre o Chile, "Crítica y Crisis en el Nuevo Cine", Iván Pinto analisa títulos referenciais para se pensar o período - El Chacal de Nahueltoro (O Chacal de Nahueltoro, 1969), de Miguel Littín; Valparaíso, mi amor (Valparaíso, meu amor, 1969), de Aldo Francia; e Tres Tristes Tigres (Três Tristes Tigres, 1968), de Raúl Ruiz -, vendo-os como desdobramentos de debates cinematográficos continentais ocorridos no país. Dessa forma, o marco ruptural em torno de 1968 se localiza em torno ao Festival de Cinema de Viña del Mar (1967 e 1969), que consolidou a ideia de que surgia um Nuevo Cine Latinoamericano. O autor busca estudar esses festivais não em sua dimensão continental, mas sim "nas condições propriamente nacionais da emergência do evento” (2016, p. 193). Pinto também recorre à noção de "geração" para entender as renovações ocorridas na cinematografia chilena decorrente da aparição de um cinema universitário no final dos anos 1950 e no decorrer dos 1960, relacionado o fenômeno à realização dos encontros de Viña. A edição de 1969, apontada normalmente como um "passo decisivo para o Nuevo Cine Latinoamericano", significou, segundo o autor, um salto qualitativo na produção chilena, o que fez desse acontecimento um marco também para o Nuevo Cine Chileno.

“En torno a Camilo Torres y el Movimiento Estudiantil" é motivado pela constatação de que o 1968 colombiano foi marcado pela presença de Camilo Torres, morto em 1966, no cinema documental da época. Sergio Becerra, articulando o contexto político ao cinematográfico, conclui que: "A ação política de massas, aberta e aglutinante, ao redor de uma Frente Unida, ou a priorização da luta armada; 
todas as opções, como todos os filmes, são atravessados pela liderança e presença do sacerdote" (2016, p. 244). O texto analisa o período entre 1966 (ano de realização de Camilo Torres Restrepo, de Diogo León Giraldo) e 1971 (data de ¿Qué es la democracia? - O que é a democracia? -, de Carlos Álvarez), quando foi realizado também Chircales (1966-1971), de Jorge Silva e Marta Rodríguez. Becerra verifica a "consolidação de um cinema político e militante" em seu país, que terá como uma de suas manifestações a criação do Cine Popular Colombiano. Essa época coincide com o fortalecimento do movimento estudantil na cena política, que terá um papel preponderante nesse "1968 cinematográfico". Para Becerra, os estudantes passaram a filmar outros estudantes e grupos, usando o cinema para criar movimentos sociais. $\mathrm{O}$ capítulo tem como mérito aliar esse diagnóstico do campo cinematográfico nacional ao encontro das estreitas pontes estabelecidas nos anos 1960 com os círculos militantes e vanguardistas europeus.

Cuba, o epicentro do NCL, é o caso tratado por Juan Antonio García Borrero em "Revolución, intelectual y cine. Notas para una intrahistoria del 68 audiovisual”. 1968, ano do centenário do início das guerras pela independência, foi marcado, por um lado, por uma série de medidas comemorativas (como o incentivo ao filme histórico); e por outro, pela emergência de um pensamento crítico no interior da Revolução. O diagnóstico de Cuba como um "guia" para os países subdesenvolvidos, discurso em evidência na época, acarretou a reflexão sobre o papel dos intelectuais (ou dos cineastas) nesse processo. García Borrero identifica quatro filmes chaves surgidos nesse contexto: Las aventuras de Juan Quinquin (As aventuras de Juan Quinquin, 1967), de Julio García-Espinosa; Memorias del subdesarrollo (Memórias do subdesenvolvimento, 1968), de Julio García-Espinosa; Lucía (1968); La primera carga al machete (A primeira carga do machete, 1969), de Manuel Octavio Gómez. Esse corpus, para o autor, é significativo de um "momento de grande inspiração coletiva”, mas também de muita tensão interna no interior do ICAIC. Trata-se de um período em que o regime endureceu o discurso sobre o engajamento político, afetando o espaço das vanguardas artísticas - fenômeno que incidiu internamente no Instituto de cinema.

O capítulo sobre o México, "El 68 cinematográfico”, escrito por Álvaro Vázquez Mantecón, tem como objetivo “[...] apresentar um panorama sobre como o movimento estudantil de 1968 transformou a maneira de conceber o cinema de uma geração de cineastas mexicanos." (2016, p. 285). Em meio ao conflito entre os estudantes e o governo, que resultaram no massacre de Tlatelolco (1968), o dispositivo documental foi visto pelos primeiros como um mecanismo de conscientização e 
intervenção política. Dessa forma, esse ano emblemático marcou uma ruptura entre cineastas e Estado, fazendo da independência uma reivindicação de muitos realizadores. Assim, o 1968 mexicano caracterizou-se pelas brigadas cinematográficas do Centro Universitario de Estudios Cinematográficos (CUEC), que ajudou a promover um cinema militante e de cunho coletivo no país. Mantecón se dedica a analisar também o contato da cinematografia mexicana do período com o NCL, que se estreitou ao final dos anos 1960, especialmente através dos festivais de Mérida (1968) e Viña del Mar (1967 e 1969). Os debates com outras práticas latino-americanas de motivações semelhantes impulsionaram ainda mais que a política passasse a ocupar um lugar central na cinematografia mexicana. Tudo isso foi determinante para que, na década de 1970, surgisse um amplo movimento de intervenção política adepto do super-8.

Por fim, o último capítulo dedicado aos casos nacionais é o de Cecília Lacruz, "La comezón por el intercambio", sobre o Uruguai. Para a autora, tradicionalmente a criação da Cinemateca do Terceiro Mundo (1969) foi vista como o início de uma série de transformações no cinema uruguaio. No entanto, para Lacruz, a própria Cinemateca é fruto de rupturas anteriores, que vinham se gestando na cinematografia do país desde o início da década. A autora se refere à aparição de um cinema político, que alcançou diferentes matizes em títulos como Carlos: cine retrato de un caminante (Carlos: cinema retrato de um caminhante, 1965), de Mario Handler, e Elecciones (Eleições, 1967), de Handler e Ugo Ulive - apontados pela historiografia vigente como marcos da integração do Uruguai ao NCL. Para ela, se há um fator de quebra a ser indicado nessa década ele estaria nas ações ligadas ao semanário Marcha, cujo Departamento de Cinema realizou o documentário Liber Arce liberarse (Liber Arce liberar-se, 1969). Ela vê, sobretudo, nos festivais promovidos pela revista (em especial as edições de 1967 e 1968), o fortalecimento de [...] uma dinâmica de cooperação e de democratização político-cultural" (2016, p. 346) que marcaria o meio cinematográfico uruguaio.

Como foi dito ao princípio desta resenha, da segunda parte de Las rupturas... o capítulo que dialoga mais diretamente com os casos nacionais apresentados é "Mérida 68. Las disyuntivas del documental”, de María Luisa Ortega. Como se pode perceber, apesar do enfoque no nacional, a maioria dos autores buscaram colocar em diálogo as cinematografias de seus países com a dos vizinhos, o que se dava principalmente nos festivais europeus e latino-americanos. Da mesma forma, Ortega procura, ao tratar do encontro venezuelano, mostrar esses espaços ao mesmo tempo como vitrine e locais de enunciação das rupturas nacionais. Se Mérida era fruto 
indireto dos festivais de SODRE ocorridos anos antes no Uruguai, por exemplo, foi a partir daí que se criou um centro de realização cinematográfica na Universidad de Los Andes (Venezuela). O festival foi pensado com base na constatação de que a identidade cinematográfica latino-americana havia sido forjada desde o exterior e que, portanto, era necessária a afirmação de um lugar de enunciação dentro da América Latina. A tese da autora é a de que Mérida 68 foi um ponto de inflexão para o Nuevo Cine Latinoamericano, a partir do qual o "novo" passou a ser indissociável do engajamento revolucionário. Essa constatação dá ao capítulo um ar de fechamento, uma vez que, realizado justamente no ano simbólico apontado pelo título - 1968 -, o festival foi palco das discussões que se gestavam em cada contexto nacional que envolviam o diagnóstico das “[...] potencialidades da experimentação estética e a vanguarda cinematográfica dos anos prévios em relação ao discurso crítico do real e o papel do documento e do testemunho em termos de sua virtual manipulação ideológica." (2016, p. 388).

É possível perceber, a partir da descrição do cerne de cada capítulo, que Las rupturas... permite ao leitor estabelecer cruzamentos entre os textos que o compõem, fazendo suas próprias sinapses entre os casos nacionais. Assim, apesar de uma escolha que abdica do enfoque transnacional, anunciada na apresentação por Mestman, justifica-se o título da obra, que recorre à ideia de um “cinema” (no singular) da América Latina. Portanto, não se abandona a noção de um processo latino-americano em voga, mas sim procura-se perceber suas diferentes vertentes. Ou, suas "rupturas", no plural, uma vez que os debates se encontram, porém, também se distanciam ao longo dos anos 1960 e 1970.

\section{Referências}

DÁVILA, I. D. V. Cámaras en trance. El nuevo cine latino-americano, un proyecto cinematográfico subcontinental. Santiago: Editorial Cuarto Propio, 2014.

FLORES, S. El Nuevo Cine Latinoamericano y su dimensión continental. Regionalismo e integración cinematográfica. Buenos Aires: Imago Mundi, 2013.

GILMAN, C. Entre la pluma y el fusil. Debates y dilemas del escritor revolucionario en América Latina. Buenos Aires: Siglo XXI, 2003.

JAMESON, F. Periodizar los 60s. Córdoba: Alción Editora, 1984.

LEÓN FRÍAS, I. El Nuevo Cine Latinoamericano de los Años Sesenta. Entre el mito político y la modernidad fílmica. Lima: Universidad de Lima; Fondo Editorial, 2013. 
MESTMAN, Mariano (coord.). Las rupturas del 68 en el cine de América Latina. Buenos Aires: 2016.

OSSA, Carlos. El ojo mecánico: cine político y comunidad en América Latina. Santiago: Fondo de Cultura Económica, 2013. 